\title{
Myocardial infarction resulting from coronary artery dissection in an adolescent with Ehlers- Danlos syndrome type IV due to a type III collagen mutation
}

\author{
Lesley C Adès, Robert D Waltham, Angelo A Chiodo, John F Bateman
}

\begin{abstract}
Ehlers-Danlos syndrome encompasses a group of inherited disorders of connective tissue, some of which are characterised by abnormalities of collagen metabolism. The chromosomal location, identified genes and biochemical defects, inheritance pattern, and clinical features for the various known subtypes are outlined. Prenatal diagnosis is possible for types IV, VI, VIIA1, and VIIA2. An unusual presentation of type IV EhlersDanlos syndrome in a 16 year old boy with an anterior myocardial infarction resulting from dissection of the left anterior descending coronary artery is reported here. A clinical diagnosis of type IV Ehlers-Danlos syndrome was made subsequently and confirmed by the reduced production, impaired secretion, and abnormally slow electrophoretic migration of type III collagen, indicating an underlying mutation in the COL3A1 gene. This patient represents the first case of type IV Ehlers-Danlos syndrome with symptomatic coronary artery dissection.
\end{abstract}

(Br Heart f 1995;74:112-116)

Medical Genetics and Epidemiology, Center for Medical Genetics, Women's and

Children's Hospital,

North Adelaide,

Australia

L C Adès

Orthopaedic

Molecular Biology

Research Unit,

Department of

Paediatrics,

University of

Melbourne, Royal

Children's Hospital,

Victoria, Australia

A A Chiodo

J F Bateman

The Royal Adelaide Hospital, Adelaide, Australia

R D Waltham

Correspondence to:

Dr L C Adès, Department of Medical Genetics and Epidemiology, Center for Medical Genetics, Women' Medical Genetics, Women's and Children's Hospital, 72 King William Road, North

Adelaide SA

Accepted for publication 21 December 1994

Keywords: Ehlers-Danlos syndrome; collagen mutation; coronary artery dissection; myocardial infarction

Ehlers-Danlos syndrome refers to a heterogeneous group of connective tissue disorders, manifested by a wide range of clinical presentations including skin fragility, skin hyperextensibility, and joint hypermobility. Fourteen distinct types have been described on the basis of clinical and genetic differences ${ }^{1}$ and the molecular basis of several of them has been identified. It is important to specify the type of Ehlers-Danlos syndrome because the natural history, clinical management, and mode of inheritance differ depending on the type. In addition to generalised involvement of the vasculature, the heart, its valves and the great vessels may also be involved in several of the Ehlers-Danlos syndrome types. Table 1 summarises the chromosomal location, identified genes and biochemical defects, inheritance pattern, and cardiovascular features of the various subtypes. ${ }^{2-4}$ Several other types have been identified besides types I-X but are not numbered as types. Approximately 80 per cent of affected individuals have type I or II, 10 per cent have type III, 4 per cent have type IV, and about 6 per cent have various other types. ${ }^{5}$

Many patients with Ehlers-Danlos syndrome-like clinical findings do not fit the general classification, and as more biochemical studies are completed, the classification is likely to expand. Important considerations from the clinical perspective include the mode of inheritance and whether the natural history can be predicted from family or biochemical studies. It is vital to distinguish the recessively inherited type VI because prenatal diagnosis is potentially available. It is also important to identify patients with type IV so that clear discussion of risks (related to sports, pregnancy, and surgery in particular) can occur in a non-emergency setting.

The evaluation of patients suspected of having Ehlers-Danlos syndrome should include careful physical examination and a detailed family history. Biochemical studies of collagens synthesised by fibroblasts cultured from full thickness dermal punch biopsy specimens can identify patients with type IV, VI, and some patients with type VII EhlersDanlos syndrome.

Type IV Ehlers-Danlos syndrome is domidiagnosis of type IV Ehlers-Danlos syndrome was made after he suffered a myocardial infarction secondary to coronary artery dissection. This is the only reported case of symptomatic coronary artery dissection in type IV Ehlers-Danlos syndrome. representing new mutations. ${ }^{1}$ It is characterised clinically by thin non-hyperelastic skin, bruising, poor wound healing, mild joint hypermobility, and spontaneous rupture of arteries, the colon, and gravid uterus, and biochemically by deficiency of type III collagen. Type III collagen deficiency results from collans in one of the genes for the type III COL $3 A 1$ mutations reported to date include genomic deletions, exon skipping, and point mutations, ${ }^{1}$ which compromise the collagen triple helix and result in impaired secretion, excessive post-translational modification, and reduced stability of the type III collagen molecules.

We report an adolescent male in whom the 
Table 1 Current classification of Ehlers-Danlos syndrome with summarised genetic and cardiological features

\begin{tabular}{|c|c|c|c|c|c|}
\hline Type & $\begin{array}{l}\text { Chromosomal } \\
\text { site }\end{array}$ & $\begin{array}{l}\text { Genene mutation and } \\
\text { biochemical defect }\end{array}$ & Inheritance & Cardiac/arterial features & $\begin{array}{l}\text { Prenatal } \\
\text { diagnosis } \\
\text { possible }\end{array}$ \\
\hline I & Unknown & Unknown & $\begin{array}{l}\mathrm{AD}, \\
\text { sporadic }\end{array}$ & $\begin{array}{l}\text { MVP, TVP, ARD/dissection, } \\
\text { ectasia of sinuses of Valsalva, } \\
\text { bicuspid aortic valve, PS, VSD, } \\
\text { ASD, vascular rupture (rare) }\end{array}$ & No \\
\hline II & Unknown & Unknown & $\mathrm{AD}$ & MVP & No \\
\hline III & Unknown & Unknown & $\mathrm{AD}$ & MVP & No \\
\hline $\mathrm{IV}^{\star}$ & $2 \mathrm{q} 31$ & $\begin{array}{l}\text { COL3A1 gene mutations; } \\
\text { abnormal type III collagen }\end{array}$ & $\mathrm{AD}$ & $\begin{array}{l}\text { AAA, multiple arterial } \\
\text { ruptures/dissections, } \\
\text { carotid-cavernous fistulas }\end{array}$ & Yes \\
\hline V & Unknown & Unknown & XLR & MVP & No \\
\hline VI & $\begin{array}{l}1 \mathrm{p} 36 \cdot 3- \\
\text { p } 36 \cdot 2\end{array}$ & $\begin{array}{l}\text { PLOD gene mutations; lysyl } \\
\text { hydroxylase deficiency in } \\
\text { some patients }\end{array}$ & AR & Arterial and aortic rupture & Yes \\
\hline VII & Unknown & $\begin{array}{l}\text { Procollagen protease } \\
\text { deficiency }\end{array}$ & AR & None & No \\
\hline VIIA1 & $\begin{array}{l}17 \mathrm{q} 21 \cdot 31- \\
\mathrm{q} 22 \cdot 05\end{array}$ & $\begin{array}{l}\text { COL1A1 gene mutations; } \\
\text { pro } \alpha 1 \text { (I) chain abnormality }\end{array}$ & $\mathrm{AD}$ & None & Yes \\
\hline VIIA2 & $7 \mathrm{q} 22 \cdot 1$ & $\begin{array}{l}\text { COLIA2 gene mutations; } \\
\text { pro } 02(1) \text { chain abnormality }\end{array}$ & $\mathrm{AD}$ & None & Yes \\
\hline $\begin{array}{l}\text { VIII } \\
\mathrm{X}\end{array}$ & $\begin{array}{l}\text { Unknown } \\
2 \mathrm{q} 34\end{array}$ & $\begin{array}{l}\text { Unknown } \\
\text { FN1 gene mutations; } \\
\text { fibronectin defect }\end{array}$ & $\begin{array}{l}\mathrm{AD} \\
\mathrm{AR}\end{array}$ & $\begin{array}{l}\text { ARt, MR } \\
\text { MVP }\end{array}$ & $\begin{array}{l}\text { No } \\
\text { No }\end{array}$ \\
\hline $\begin{array}{l}\text { Type Hernandez } \\
\text { (progeroid form) }\end{array}$ & Unknown & $\begin{array}{l}\text { Defective proteodermatan } \\
\text { sulphate biosynthesis }\end{array}$ & $\mathrm{AD}$ & AS, PS & No \\
\hline $\begin{array}{l}\text { Unspecified type } \\
\text { Unspecified type }\end{array}$ & $\begin{array}{l}\text { Unknown } \\
\text { Unknown }\end{array}$ & $\begin{array}{l}\text { Unknown } \\
\text { Unknown }\end{array}$ & $\begin{array}{l}\mathrm{AR} \\
\mathrm{AD}\end{array}$ & $\begin{array}{l}\text { AA } \\
\text { AA, cystic medial necrosis } \\
\text { of aorta, and myxomatous } \\
\text { degeneration of mitral } \\
\text { and tricuspid valves }\end{array}$ & $\begin{array}{l}\text { No } \\
\text { No }\end{array}$ \\
\hline
\end{tabular}

*There is possibly one other $\mathrm{AD}$ and two AR subtypes of type IV Ehlers-Danlos syndrome.

$A D$, autosomal dominant; MVP, mitral valve prolapse; TVP, tricuspid valve prolapse; ARD, aortic root dilatation; AAA, abdominal aortic aneurysm; XLR, $X$ linked recessive, AR, autosomal recessive; ARt, aortic regurgitation; $M R$, mitral regurgitation; AS, aortic stenosis; PS, pulmonary stenosis; AA, aortic aneurysm; VSD, ventricular septal defect; ASD, atrial septal defect.

\section{Materials and methods}

FIBROBLAST COLLAGEN BIOSYNTHETIC LABELLING

Dermal fibroblast cultures were established and maintained as previously described..$^{56}$ After culture for 3 days in growth medium containing $0.25 \mathrm{mmol} / 1$ sodium ascorbate (Sigma), confluent fibroblast cultures were labelled with $10 \mu \mathrm{Ci} / \mathrm{ml} \mathrm{L}-\left[5-{ }^{3} \mathrm{H}\right]$ proline (30 $\mathrm{Ci} / \mathrm{mmol}$; Amersham) for $18 \mathrm{~h}$ in medium containing 10 per cent $(\mathrm{v} / \mathrm{v})$ dialysed fetal calf serum (Flow Laboratories, North Ryde, NSW, Australia) and $0.25 \mathrm{mmol} / 1$ sodium ascorbate. The cell layer and medium fractions were separated for analysis and the procollagens, precipitated with 25 per cent saturated ammonium sulphate, were subjected to limited proteolysis with pepsin..$^{56}$

Collagen $a$ chains were resolved by sodium dodecylsulphate/polyacrylamide gel electrophoresis on 5 per cent $(w / v)$ separating gels containing $2 \mathrm{~mol} / \mathrm{l}$ urea, using the delayed reduction technique ${ }^{7}$ to resolve the type III collagen $a$ chains. Collagen bands were detected by fluorography. ${ }^{8}$ Radioactivity in the collagen bands was quantified by excision and scintillation counting to assess collagen metabolism. ${ }^{9}$

\section{Clinical report}

The patient had a past history of severe congenital bilateral talipes equinovarus, recurrent epistaxes, a tendency to keloid scar formation, and rectal bleeding. At 16 years of age, while at his school desk, he developed a gradual onset of central chest pain associated with dyspnoea, sweating, and nausea. He was transferred to hospital where no abnormality was found on clinical examination of the cardiovascular system. An electrocardiogram demonstrated $Q$ waves in leads $I, a V L$, and V3-4 with $T$ wave inversion. Aortic dissection was considered. A thoracic computed tomogram gave equivocal results. A transoesophageal echocardiograph showed a normal aortic root with hypokinesis of the septum and anterior left ventricular wall. Total serum creatine kinase $(\mathrm{CK})$ peaked at $2809 \mathrm{U} / 1$ (normal range for males 60-270 $\mathrm{U} / \mathrm{l}) 12 \mathrm{~h}$ from the onset of pain; CK-MB (muscle brain fraction) was $182 \mathrm{U} / 1$ (normal range $<10 \mathrm{U} / \mathrm{l}$ ) and $\mathrm{CK}$ total: CK-MB 6.5 per cent (normal $<4$ per cent). A diagnosis of anterior myocardial infarction was made. Thrombolytic treatment was not given. Serum electrolytes, serum cholesterol, triglycerides, anticardiolipin antibodies, liver function studies, $\beta$-human chorionic gonadotropin, extractable nuclear antigen, alphafetoprotein, antinuclear factor, full blood count, and coagulation profile were all normal. The total serum CK returned to normal by the sixth day at which time coronary angiogram (fig 1) demonstrated dissection of the proximal left anterior descending coronary artery; anterior myocardial infarction was presumed secondary to coronary artery dissection. A connective tissue disorder was suspected. The patient was managed conservatively with aspirin $150 \mathrm{mg}$ daily and recovered.

When seen in the genetics clinic 6 weeks after his initial presentation, his height was $162.8 \mathrm{~cm}$ (3rd centile) and weight $52.2 \mathrm{~kg}$ (10th centile). He had prominent eyes, conjunctival injection, a violaceous hue to the eyelids, a "pinched" nose, and slight dental overcrowding. There was mild joint hypermobility of the proximal interphalangeal joints. The skin over his elbows and neck was thin and translucent but not hyperelastic. He had numerous keloid scars. The patient suffered 
Figure 1 Coronary angiogram (right anterior oblique view) of the patient described in the text 6 days after presentation showing dissection of the proximal left anterior descending coronary artery, with origin of the dissection just beyond the left main coronary artery (arrow).

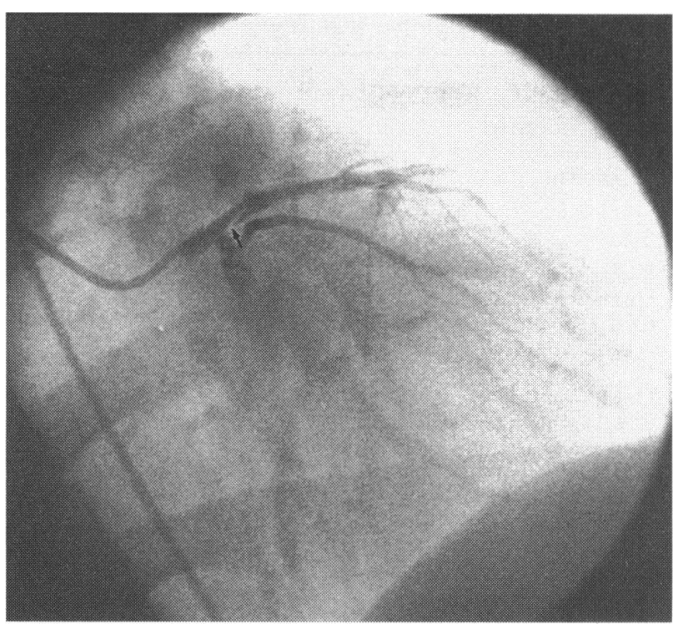

another episode of acute chest pain 1 year after original presentation; thoracic computed tomogram was normal. He was managed conservatively and given atenolol.

The patient's older brother also had severe bilateral talipes equinovarus at birth. Pyloric stenosis was corrected surgically at 1 month of age. He had a history of easy bruising and bleeding, a tendency to keloid scar formation, and suffered recurrent dislocations of his right shoulder. $\mathrm{He}$ had numerous surgical procedures to his feet. At 12 years of age he suffered abdominal trauma during sport; haemoperitoneum was found at laparoscopy and possible splenic rupture was diagnosed. $\mathrm{He}$ was managed conservatively and recovered.

On examination at 19 years of age his height was $171.6 \mathrm{~cm}$ (10th-25th centile) and weight $56 \cdot 25 \mathrm{~kg}$ ( $3 \mathrm{rd}-10$ th centile). He had a thin, aesthenic build and the same facial features as his brother, but with prominent venous patterning over the forehead. The skin was thin and translucent and numerous hypertrophic scars were present. $\mathrm{He}$ had marked joint hypermobility of the small joints of his hands, a contracture of the proximal interphalangeal joint of the left little finger, and bilateral pes planus. Cardiovascular examination was normal.

The patient's mother had been a slightly built woman whose photographs showed a facies unlike that of her brother or parents. She had prominent eyes, a violaceous colouring to the eyelids, a "pinched" nose, and thin lips. She bruised easily, had a tendency to keloid scar formation, and had hypermobility of the small joints of her hands. At 28 years of age she suffered a spontaneous perforation of the bowel, and died soon afterwards from spontaneous rupture of an isolated right vertebral artery aneurysm. These findings were confirmed at postmortem examination but no diagnosis was assigned. The heart, aorta, and coronary, cerebral (excluding the right vertebral), renal, and pulmonary arteries were normal at postmortem examination.

\section{Results}

Biochemical studies on the patient's cultured dermal fibroblasts provided evidence of a type III collagen defect. Fibroblast collagen production was assessed by biosynthetic labelling and quantitative electrophoresis (table 2). Type III collagen production in our patient was reduced to 32 per cent of control type III collagen production. This dramatic reduction in type III collagen was reflected in the reduced proportion of type III to type I collagen production ( 4.4 per cent) relative to control fibroblast values ( 11.6 per cent). Type III collagen secretion was also greatly impaired ( 36.3 per cent) compared with that of control cells from which 95.8 per cent of type III collagen was secreted during the labelling period. Type I collagen secretion by the type IV Ehlers-Danlos syndrome cells was normal. As collagen secretion is critically dependent on the efficient folding of the three component proal(III) chains into a triple helix, these data suggest that helix formation is disturbed with a consequent increased intracellular degradation of mutant type III collagen resulting in reduced type III collagen production during the labelling period. While increased degradation was not directly demonstrated in this case, it has been a commonly observed phenomenon with type I collagen mutations in osteogenesis imperfecta in which collagen monomer assembly and helix formation are perturbed. ${ }^{510}$

Type III collagen $a 1$ (III) chains from our patient also exhibited slow electrophoretic migration (fig 2). Slow electrophoretic migration of collagens is caused by increased levels of post-translational modified lysine residues ${ }^{5}$ due to underlying structural mutations disturbing efficient assembly of the triple helix and exposing the unfolded $a$ chains to increased enzymatic modification. ${ }^{6}$

These data indicate the presence of structural mutation in the gene for the proal(III) chain of type III collagen (COL3A1) in this case of type IV Ehlers-Danlos syndrome. Characterisation of the precise mutation is in progress.

\section{Discussion}

Several types of Ehlers-Danlos syndrome are known to be associated with cardiovascular or arterial disease, or both (table 1). Other features, unrelated to the heart or vasculature, occur with a wide variation in the clinical manifestations, depending on the particular type.

In type I Ehlers-Danlos syndrome (gravis type), there is marked skin involvement with 
Figure 2 Electrophoresis of pepsin digested fibroblast collagens. Fibroblast cultures from a control (C) and the patient with Ehlers-Danlos syndrome (ED) were labelled with tritiated L-proline for $18 \mathrm{~h}$. Cell layer (CELL) and secreted collagens (MED) were digested with pepsin and analysed after delayed reduction ${ }^{7}$ on sodium dodecylsulphatel polyacrylamide gels (5 per cent) (see materials and methods section for details). The migration positions of type I collagen a1(I) and $a 2$ (I) and type III collagen a1(III) chains are shown.

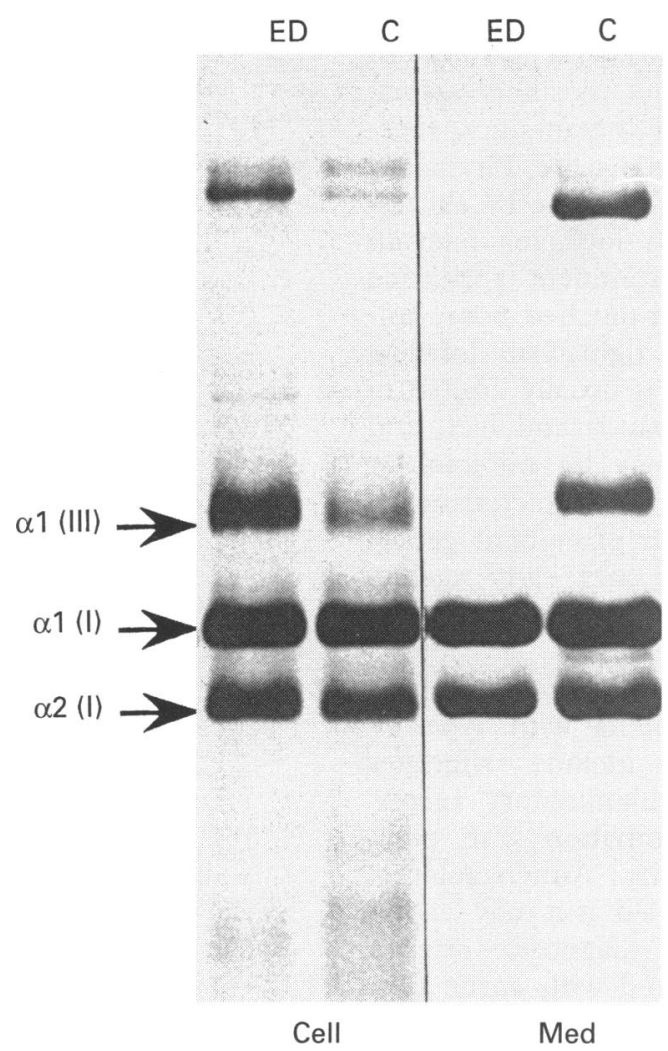

atrophic scars, generalised gross joint laxity, musculoskeletal deformity, diverse orthopaedic complications, and retinal detachment. Internal complications such as spontaneous bowel rupture and premature rupture of membranes in pregnancy may occur; aortic dissection has been reported. ${ }^{11}$ Type II Ehlers-Danlos syndrome is associated with soft velvety skin and mild joint hypermobility, while individuals with type III have marked joint hypermobility, recurrent joint dislocations, but normal scarring of the skin. In type IV Ehlers-Danlos syndrome some individuals have a characteristic facies with apparent prominence of the eyes because of paucity of periorbital fat and a "pinched" appearance to the nose. Other features include thin skin with prominence of superficial veins and marked bruising. The joints are usually normal. Bowel and uterine rupture may occur and the life expectancy is shortened.

Type V Ehlers-Danlos syndrome is associated with skin hyperextensibility and a tendency to bruise easily. Type VI Ehlers-Danlos syndrome is otherwise known as the ocularscoliotic subtype. It is characterised by progressive kyphoscoliosis from birth, microcornea, and fragility of ocular tissues leading to rupture of the globe or retinal detachment. The natural history regarding the vascular system is not well known. In type VII EhlersDanlos syndrome there is severe joint hypermobility, mild skin hyperextensibility, and mild bruising. The phenotype may include short stature, epicanthic folds, a depressed nasal bridge, and micrognathia. Periodontal disease, marked bruising, joint hypermobility, and skin hyperextensibility are features of type VIII. Striae densae are seen in patients with type $\mathrm{X}$. The progeroid form of Ehlers-
Danlos syndrome (type Hernandez) is characterised by mental retardation, short stature, progeroid facies, redundant skin, atrophic scars, joint hypermobility, pectus excavatum, and osteopenia. Mental retardation, marked joint hyperextensibility and dislocations, hyperelastic, redundant skin, inguinal hernias, deafness, and cataracts occur in the unspecified autosomal recessive type EhlersDanlos syndrome. The autosomal dominant unspecified subtype is characterised by facial asymmetry, micrognathia, hernias, and kyphoscoliosis.

Vascular complications lead to significant morbidity and mortality in patients with Ehlers-Danlos syndrome, particularly in those with types I, IV, and VI. Spontaneous rupture of large arteries, ${ }^{12-14}$ intracranial aneurysms, and arteriovenous fistulae ${ }^{1516}$ are all typical of type IV, but may also occur in types I and VI, sometimes even in persons with minimal external findings. ${ }^{17}$ Arterial bleeding usually occurs after puberty and appears to be more common in young men. The most common locations of arterial bleeding are in the abdominal cavity and involve the small arteries rather than the aorta itself.

Coronary artery aneurysms have been reported in four unrelated adults with type IV Ehlers-Danlos syndrome. Saccular aneurysms of the right coronary artery, filled with thrombi, have been described in association with a history of myocardial infarction and with aneurysms of the cerebral vessels, upper and lower limb arteries, and splenic and mesenteric arteries. ${ }^{18}$ In the patient reported by $\mathrm{Di}$ Mario et $a l^{19}$ the aneurysms had a smaller diameter, were fusiform, without angiographic evidence of mural thrombosis, and involved the right and left coronary arteries. Fusiform aneurysmal dilatations of the coronary arteries have been described in association with idiopathic mitral valve prolapse, ${ }^{20}$ but not in the context of the multiple cardiovascular manifestations of the Ehlers-Danlos syndrome. Imahori et $a l^{21}$ reported a woman with type IV Ehlers-Danlos syndrome who suffered a series of episodes of arterial disease characterised by the formation of multiple aneurysms and rupture of medium sized arteries. The vascular episodes occurred over several years and included left carotid-cavernous fistula, symmetric aneurysms of both radial arteries, and "transient" aneurysmal lesions of the left superficial temporal arteries, left posterior tibial, and right anterior tibial arteries. The patient died of acute rupture of a splenic artery aneurysm at age 42 years. Aneurysms of the right coronary, superior mesenteric, and intracranial arteries were also found at necropsy. Coronary artery aneurysms have been reported on one other occasion in type IV. ${ }^{19}$ This was a chance finding in an asymptomatic 48 year old man being investigated for non-penetrating chest trauma, in whom multiple coronary artery aneurysms, mitral valve prolapse, fusiform dilatation of the ascending aorta with moderate insufficiency, and left anterior hemiblock were found. ${ }^{19}$ 
The importance of proper diagnosis of type IV Ehlers-Danlos syndrome is paramount because the morbidity and mortality associated with diagnostic and therapeutic procedures are increased in this disease. Physicians considering the possibility of type IV EhlersDanlos syndrome should look for relevant clinical signs such as prominent appearing eyes, a thin, delicate, and pinched nose, hollow cheeks, thin lips, and tight, firm, lobeless ears. Joint hypermobility is usually limited to the small joints of the hands and feet, and skin hyperextensibility may be minimal or absent in adults. The skin is characteristically thin and translucent with prominent generalised venous patterning and early ageing. These features may be very subtle in some patients.

Drugs that should be avoided or used with extreme caution in patients with type IV Ehlers-Danlos syndrome include salicylates and non-steroidal anti-inflammatory agents, either alone or in combination with penicillins and cephalosporins. Anticoagulation treatment should be avoided as it may lead to fatal bleeding. ${ }^{1}$ Routine diagnostic arteriography has been associated with aortic rupture, ${ }^{1622}$ arterial dissection, ${ }^{22}$ and massive haemorrhage from arterial puncture sites, ${ }^{15}$ even when the diagnosis has been established before investigation. Profuse bleeding and expanding haematomas are commonly reported results of arterial puncture despite normal levels of platelet and coagulation factors. The extreme vascular fragility of this disease cannot be overemphasised. Complications occur in about 65 per cent of patients subjected to angiography. ${ }^{1623}{ }^{24}$ In retrospect, aspirin should not have been used in the management of our patient and angiography placed him at considerable risk. Conservative treatment, whenever possible, is recommended.

Our patient represents the first case of type IV Ehlers-Danlos syndrome with symptomatic coronary artery dissection and myocardial infarction. Physicians should consider type IV Ehlers-Danlos syndrome in the differential diagnosis of myocardial infarction secondary to (coronary) arterial dissection, as diagnosis of this heritable disorder has specific implications for management, prognosis, and recurrence risk counselling. The diagnosis can be confirmed by biochemical analysis of type III collagen from the patient's cultured dermal fibroblasts.
We thank Dr M Hart for referring the family to the Genetics Department, Dr E Haan for his valuable comments, and the family for their cooperation. This work was supported by grants from the National Health and Medical Research Council of Australia.

1 Steinmann B, Royce PM, Superti-Furga A. The EhlersDanlos syndrome. In: Royce PM, Steinmann B, eds. Danlos syndrome. In: Royce PM, Steinmann B, eds. Connective tissue and its heri
Wiley-Liss, 1993:351-407.

2 McKusick VA, Amberger JS. The morbid anatomy of the human genome: chromosomal location of mutations causing disease. $f$ Med Genet 1994;31:265-79.

3 Wilkie AOM, Amberger JS, McKusick VA. A gene map of congenital malformations. $\mathcal{F}$ Med Genet 1994;31: 507-17.

4 McKusick VA. In: Mendelian inheritance in man. A catalog of human genes and genetic disorders. 11 th ed. Baltimore: The John Hopkins University Press, 1994.

5 Bateman JF, Mascara T, Chan D, Cole WG. Abnormal type I collagen metabolism by cultured fibroblasts in lethal perinatal osteogenesis imperfecta. Biochem $\mathcal{F} 1984$; 217:103-15.

6 Bateman JF, Chan D, Mascara T, Rogers JG, Cole WG. Collagen defects in lethal perinatal osteogenesis imperfecta. Biochem $\mathcal{F}$ 1986;240:699-708.

7 Sykes B, Puddle B, Francis M, Smith R. The estimation of two collagens from human dermis by interrupted gel electrophoresis. Biochem Biophys Res Commun 1976;72: 1472-80.

8 Bonner WM, Laskey RA. A film detection method for tritium-labelled proteins and nucleic acids in polyacrylamide gels. Eur $\mathcal{F}$ Biochem 1974;46:83-8.

9 Bateman JF, Harley V, Chan D, Cole WG. Bateman JF, Harley V, Chan D, Cole WG. using ${ }^{3} \mathrm{H} /{ }^{14} \mathrm{C}$ proline dual-labelling and polyacrylamide using ${ }^{3} \mathrm{H}^{14} \mathrm{C}$ proline dual-labelling and polyacryla
gel electrophoresis. Anal Biochem 1988;168:171-6.

10 Byers PH. Osteogenesis imperfecta. In: Royce PM, Steinmann B, eds. Connective tissue and its heritable disorders. New York: Wiley-Liss, 1993:317-50.

11 McKusick VA. The Ehlers-Danlos syndrome. In: Heritable disorders of connective tissue. 4th ed. Saint Louis: CV Mosby, 1972:292-371.

12 Freiberger HF, Pinnell SR. Heritable disorders of connective tissue. In: Moschella SL, ed. Dermatology update. tive tissue. In: Moschella SL, ed.

13 Mories A. Ehlers-Danlos syndrome with a report of a fatal case. Scott Med $\mathcal{f}$ 1960;5:269-72.

14 McFarland W, Fuller DE. Mortality in Ehlers-Danlos syndrome due to spontaneous rupture of large arteries. N Engl f Med 1964;271:1309-10.

15 Graf CJ. Spontaneous carotid-cavernous fistula. Arch Neurol 1965;13:662-72.

16 Schoolman A, Kepes JJ. Bilateral spontaneous carotidcavernous fistulae in Ehlers-Danlos syndrome. $\Im$ Neurosurg 1967;26:82-6.

17 Shohet I, Rosenbaum I, Frand M, Duksin D, Engelberg $S$, Goodman RM. Cardiovascular complications in the Ehlers-Danlos syndrome with minimal external findings. Clin Genet 1987;31:148-52.

18 Konecke LL, Spitzer S, Mason D, Kasparian H, James $\mathrm{PM}$. Traumatic aneurysm of the left coronary artery. Am f Cardiol 1971;27:221.

$19 \mathrm{Di}$ Mario C, Zanchetta M, Maiolino P. Coronary aneurysms in a case of Ehlers-Danlos syndrome. $F_{p} n$ Heart $\mathcal{F} 1988 ; 29(4): 491-6$.

20 Freeman JT. Ehlers-Danlos syndrome. Am $f$ Dis Child 1950;79:1049-50.

21 Imahori S, Bannerman RM, Graf CJ, Brennan JC. EhlersDanlos syndrome with multiple arterial lesions. $A m \mathcal{F}$ Med 1969;47:967.

22 Lach B, Nair SG, Russell NA, Benoit BG. Spontaneous carotid-cavernous fistula and multiple arterial dissections in type IV Ehlers-Danlos syndrome. Case report. tions in type IV Ehlers-Danlos

23 Cikrit DF, Miles JH, Silver D. Spontaneous arterial perforation: the Ehlers-Danlos specter. $f$ Vasc Surg 1987; 5:248-55.

24 Krog M, Almgren B, Eriksson I, Nordström S. Vascular complications in the Ehlers-Danlos syndrome. Acto Chirurgica Scandinavica 1983;149:279-82. 